\title{
EMERGENCY FIRST AID RESPONDERS SYSTEM, AS AN OPPORTUNITY TO SUPPORT THE STATE MEDICAL RESCUE SYSTEM IN WROCLAW
}

\author{
Pawel Gawlowski ${ }^{1}$, Kamil Kedzierski' ${ }^{2}$, Sandra Pyda ${ }^{3}$ \\ 1 Department of Emergency Medical Service, Wroclaw Medical University, Poland \\ ${ }^{2}$ State Fire Brigade, District headquarters, Nysa, Poland \\ ${ }^{3}$ Polish Society of Disaster Medicine, Warsaw, Poland
}

\begin{abstract}
A person in a life-threatening situation is dependent on the first people at the scene of the event. The effectiveness of the rescue operations depends on the level of their training and willingness to help. The availability of professional services statutorily appointed to provide assistance is often insufficient. This is due to the failure of the system at all stages. Currently, work is carried out around the world to shorten the time of reaching people who have knowledge and skills in the field of first aid. This will allow us to take action in the first minutes that determine the survival when the victim is in a life-threatening situation. One of the tested solutions is the creation of mobile applications used by volunteers educated in the field of performing activities in the area of first aid in a life-threatening situation of the victim.
\end{abstract}

KEY WORDS: first aid, volunteer, mobile application, rescue system

Disaster Emerg Med J 2018; 3(2): 56-60

\section{ADMISSION}

Elapsed time is the biggest threat to an injured person in life-threatening situations. Continuous development of medicine, better equipment and knowledge, and experience regarding the treatment of emergencies among medical personnel will not have a chance of existence if a modern ambulance with a professional and well-trained crew will reach the scene after 15 minutes, during which no one will take care of the injured. There are many life-threatening conditions in which treatment should be started immediately, and every minute that passes adversely affects the victim [1]. Such conditions include: sudden cardiac arrest, traumatic or non-traumatic airway obstruction, or massive hemorrhage. The above life-threatening conditions have one thing in common: they usually end in death or permanent disabil- ity if the appropriate measures are not implemented within the first 3-5 minutes [2].

The chances that the Medical Rescue Team will reach us in less than 5 minutes are very small. This is due to the increasing traffic on roads (traffic jams), various dislocation of ambulances, and poor public knowledge, which very often calls Medical Emergency Teams to situations that do not require their intervention. All these factors contribute to the fact that we often have to wait for an ambulance for more than 10 minutes, and there are situations where the dispatcher is forced to send other units, such as the State Fire Service, due to the lack of available Medical Rescue teams for medical events [3].

An analysis of the survival chain shows that the first three links are created by witnesses of the event (often unfortunately unprepared for first aid at a high 
level) [4]. This is another argument for the fact that in addition to modern equipment and qualified personnel, we need conscious society that is not afraid and able to provide first aid.

\section{EMERGENCY FIRST AID RESPONDERS (EFAR)}

In many places around the world there are solutions that allow sending qualified help to an injured person at a faster time than an ambulance. There are solutions which work well in the everyday activities of emergency services, and most importantly, they definitely give greater chances of survival for the injured in various types of events. One of such solutions is the introduction of the so-called First Aid Responders (FAR), i.e. people trained in First Aid with a special application allowing for dispatch to events in public places, in situations where the GPS system indicates that the First Aid Responder will be faster on the spot than ambulances. This solution has been successfully used for many years, among others in Canada, the United States, France, Great Britain and Israel. Depending on the country, First Aid Responders have different powers and equipment [5].

One of the leading countries in the implementation of the above system is Israel. Magen David Adom (The Red Star of David) is the only institution that deals with Emergency Medical Services in Israel. There are more than 12,000 volunteers and nearly 2,000 fulltime employees, of whom around 3,000 are active First Aid Responders. Anyone who is at least 16 years of age and has completed a minimum 60 -hour basic course in First Aid may become a member of the system. In addition, each volunteer must have a minimum of two shifts per month in an ambulance (as an additional member of the team) and pass a short course once a year confirming their skills. Among the FAR are also active Emergency Medical Technicians (EMT), Paramedics, Doctors and other medical personnel. People with a medical education can also take duties on rescue scooters, or ride in ambulances under the so-called additional roster (voluntary work). It often happens that the First Aid Responder takes an ambulance or a rescue scooter in the morning and moves around the city or parks it near their workplace. Thanks to such solutions, whenever the need arises, help can be sent to the event at any time (Fig. 1).

Analyzing the possible obstacles that an ambulance may encounter on its way (traffic jams, narrow streets) statistically, the EFAR will arrive much faster to the victim, whether they are near the scene by chance

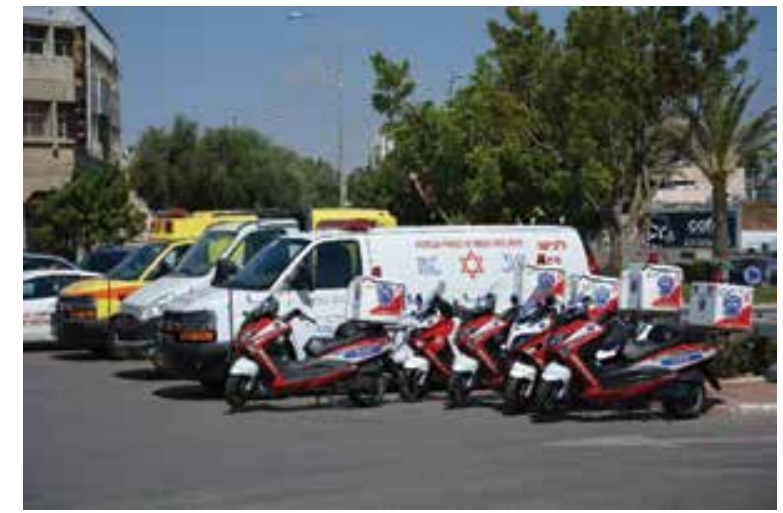

FIGURE 1. Cars and scooters Magen David Adom

or have been simply volunteering on a scooter or rescue bike near the event. Examples of Israeli services show that due to EFAR, the time from cardiac arrest to the first rhythm analysis is on average from 3 to 5 minutes [6].

\section{EMERGENCY FIRST AID RESPONDERS IN WROCLAW}

Following the system operating in Israel, a database of people willing to act was built. At the moment, it has over 100 people, communicates with the Voivodship Office, and searches for additional sources of financing, including sponsors who could cover the costs of training and basic equipment, which volunteers would have with them. An additional advantage of undertaking cooperation between the Emergency Service in Wroclaw and volunteers acting as First Aid Responders would be the possibility of joining them to Ambulance Services (as an additional member of the team). Such a solution would primarily support two-person basic teams of the Ambulance Service and First Aid Responders would allow them to gain experience. Of course, the sensitive issue of this system concerns the legal responsibility of volunteers and the scope of their duties.

\section{THE E-POSEJDON24 APPLICATION}

The application consists of two panels: a dispatcher's panel and a user's mobile application. The following part of the thesis shows possible solutions for all links in the system being written.

The dispatcher's stand has an individual login and password, thanks to which the dispatcher has access to the system. The process of having a volunteer available can be done via a website. After logging into the system, the dispatcher can see how many active vol- 
unteers he has in his area of activity. However, in order to protect personal data, he does not see their exact location. Additionally, after clicking on a specific volunteer (described by an individual number), he has a preview regarding their level of knowledge (Lifeguard, Paramedic, Doctor). Thanks to such a solution, the dispatcher can see how many people he can rely on, and the volunteers are provided with privacy, because no one can trace their current position. This solution also allows for rational management of battery energy in the volunteers telephone. After receiving the notification by the emergency number, the dispatcher creates a new event in the application menu. After entering the address or GPS coordinates, the location of the event appears immediately on the map. Then, the dispatcher can enter information about the incident, e.g. "car accident" or "male, lying, unconscious" and additional information if he deems it necessary. It is worth mentioning here that the dispatcher does not send any sensitive data in the notification, such as the name, surname or telephone number of the reporting person. After completing the order entry, the system searches the area for the next 5 volunteers and automatically sends them the ALARM information along with the location of the request and its content. At the moment when the volunteer accepts the notification, their location will also appear on the event map along with the preferred way of reaching (car, on foot) and the expected time of arrival. In addition, the dispatcher in the volunteer panel will see their phone number so that he can directly connect to them if necessary. Every volunteer's activity (on the road, on the spot, help needed, connection with the dispatcher) is recorded by the system along with the exact time, so that it is possible to verify the event. If the volunteer decides to take a picture, information will appear on the dispatcher's panel, and the dispatcher will be able to see how the place of the event looks like (an extremely useful tool for large accidents and other events with a large number of injured people). The volunteer will also be able to telephone directly the person who ordered it. If no volunteer signs up within $2 \mathrm{~km}$ from the event, the system will automatically start looking for more people who are closest to the place of the event (Fig. 2). After the action has been completed, the dispatcher will receive an automatically generated report from the event.

Access to the mobile application may be held by a person who declared that he was a member of the rescue organization and signed an appropriate voluntary service agreement, which defines the rights

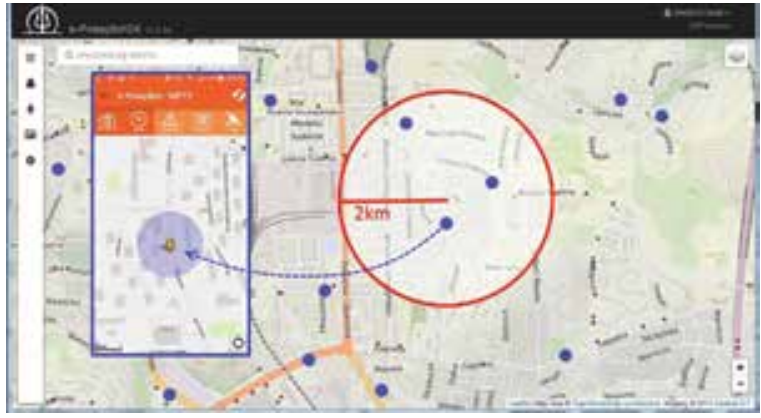

FIGURE 2. Dispatcher's panel with volunteer's positions

and duties of the volunteer, as well as the scope of their competence during the activities. This solution is aimed at verifying the disposition of persons to events and the possibility of insuring them against the consequences of accidents during the provision of assistance. A volunteer may be a rescuer with current KPP rights, a paramedic, a nurse and a doctor. The application will be downloaded via an individually generated link from the project website. Access to the application will be full at the time the volunteer has the current permissions. If the volunteer's rights are time-barred, e.g. Qualified First Aid course or a volunteer fails to report for obligatory periodic training, the application will inform him or her about the lack of access. Further action will be possible only after completing the deficiencies by the volunteer. The application works on the Android system and requires Internet access. The location is set via a GPS transmitter and Wi-Fi coverage. Thanks to the use of the time location and limiting data collection by the system, the application should reasonably manage the battery resources in the volunteer's telephone. The volunteer logs in to the application by selecting the "I'm online" option. At this moment, he appears on the dispatcher's panel list and can be sent to the event if the need arises. The volunteer does not have access to currently ongoing events in which he does not take part.

When the system locates the volunteer in the closest place to the event, it will automatically send a message to him: NOTE ALARM (Fig. 3). At this moment, information about the place of the incident and the reason for the notification will appear on the application panel. In addition, the screen displays 4 possibilities of action: I confirm participation - on foot, I confirm participation - by car, I am busy and connecting with the dispatcher. After confirming the option: "I confirm participation", the user is automatically redirected to the map, which will choose the nearest route to him (depending on the selected 


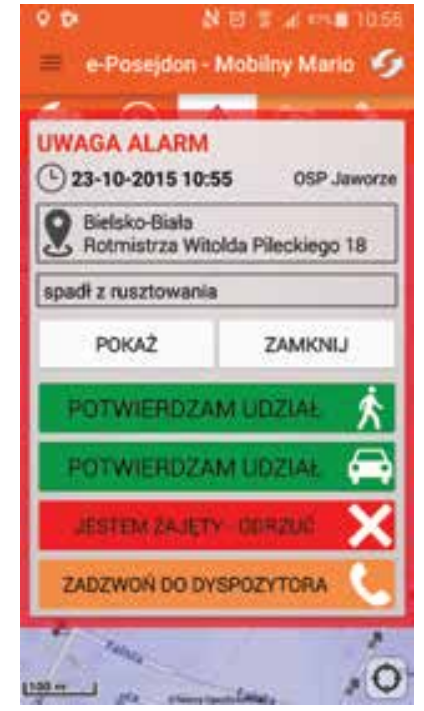

FIGURE 3. Main panel

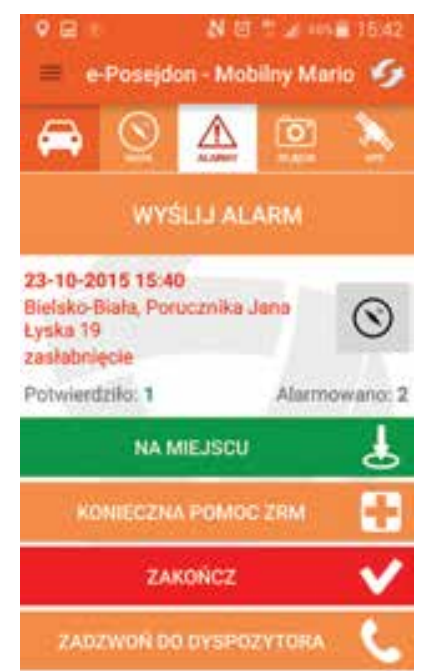

FIGURE 4. On the scene of the event

option: foot/car), location and route will also be marked on the dispatch panel.

If the user decides to reject the message, the dispatcher will also be informed; additionally the volunteer is removed from the event map. After selecting this option, the rescuer is not able to re-enter the event, but he is still in the system and can be disposed once again if the need arises.

After reaching the scene, the rescuer informs the dispatcher about it by clicking on the icon: on the spot (Fig. 4). This is the first action to be taken at the scene of the incident. Then the rescuer can proceed with first aid. In addition, there is an option to confirm the need to dispose of an ambulance or other emergency services, take a picture of the scene of the incident as well as a telephone connection with the dispatcher. After transferring the victim to the emergency rescue service, the "end operation" option is selected, which will generate an automatic report from the event.

Every volunteer, at the moment in which he or she decides to be online, is obliged to carry a reflective band or reflective vest (if he is in a car), disposable gloves, a resuscitation mask, NRC foil and $2 \times 1$ gauze. In addition, they may have other medical equipment, but its use may not exceed the scope of its rights. A volunteer in the system has an individually assigned identification number under which they operate when they are online. The dispatcher has no access to the volunteer's personal data. If for any reason there is a need to identify the volunteer's personal data, this is done only by persons entitled to full access to the database and after informing the volunteer about the reasons for doing so. In addition, each volunteer will receive information once a month with the report of events along with the analysis of volunteer activities (described with the help of identification numbers).

\section{ADDITIONAL EFAR BENEFITS}

The use of Emergency First Aid Responders in the daily activities of emergency services is just one of the advantages of having a group of volunteers cooperating with the system. Emergency services are more and more often confronted with the challenge of dealing with situations where there are many people injured and the rescuers needed to provide help are missing.

Having a group of trained and capable rescuers ready to appear at the scene within a few minutes of the alarm is a comfort in times of which both the threat of terrorist attacks and mass accidents are increasing. EFAR called to the place of a mass accident is an extra pair of hands and additionally, special hands because they are trained in giving qualified first aid. We can use such people as additional members of teams providing help to victims in serious conditions, as well as care for victims with light injuries (small wounds, psychological care). They can also help to secure the place of the incident or other activities that improve the operation of rescue operations.

\section{CONCLUSIONS}

The introduction of the EFAR system in Wroclaw can significantly accelerate the assistance to people in life-threatening situations, which can 
be of key importance in the prognosis and survival of the victims. Both the Ambulance Service in Wroclaw and other units cooperating with the system can benefit from such cooperation. Dissemination of knowledge about first aid, as well as professional development of people who want to work within this project, including individuals not working in the profession, will raise their level of knowledge as well as the level of security of the inhabitants of Wroclaw. The system is ready for operation, checked and improved for many years in various countries around the world. Therefore, it is worth using ready-made solutions and modifying them to legal conditions prevailing in a given country.

\section{REFERENCES}

1. Wytyczne resuscytacji. Andres J. (red.). Polska Rada Resuscytacji. Kraków 2015.

2. Campbell J, Alson R. ITLS Ratownictwo przedszpitalne w urazach. Medycyna Praktyczna. Kraków 2017.

3. Główny Urząd Statystyczny. Działalność Systemu Państwowego Ratownictwa Medycznego w 2017 roku. Warszawa 2018.

4. Plantz S, Wifler E. Medycyna ratunkowa. Elsevier Urban \& Partner. Wrocław 2008.

5. Anderson GS, Gaetz M, Masse J. First aid skill retention of first responders within the workplace. Scand J Trauma Resusc Emerg Med. 2011; 19: 11, doi: 10.1186/1757-7241-19-11, indexed in Pubmed: 21303536.

6. Magen David Adom in Israel 2018. www.mdais.org. 